Article

\title{
Long-Term Evolution of the SUHI Footprint and Urban Expansion Based on a Temperature Attenuation Curve in the Yangtze River Delta Urban Agglomeration
}

\author{
Fei Tao ${ }^{1,2,3,4,+}$, Yuchen $\mathrm{Hu}{ }^{1,3,4,+}$, Guoan Tang ${ }^{1,3,4, *}$ and Tong Zhou ${ }^{2}$ (D) \\ 1 School of Geography, Nanjing Normal University, Nanjing 210023, China; taofei@ntu.edu.cn (F.T.); \\ 1722021034@stmail.ntu.edu.cn (Y.H.) \\ 2 School of Geographical Sciences, Nantong University, Nantong 226007, China; zhoutong@ntu.edu.cn \\ 3 Key Laboratory of Virtual Geographic Environment (Nanjing Normal University), Ministry of Education, \\ Nanjing 210023, China \\ 4 Jiangsu Center for Collaborative Innovation in Geographical Information Resource Development and \\ Application, Nanjing 210023, China \\ * Correspondence: tangguoan@njnu.edu.cn; Tel.: +86-137-7662-3891 \\ + These authors equally contributed to the work.
}

Citation: Tao, F.; Hu, Y.; Tang, G.; Zhou, T. Long-Term Evolution of the SUHI Footprint and Urban Expansion Based on a Temperature Attenuation Curve in the Yangtze River Delta Urban Agglomeration. Sustainability 2021, 13, 8530. https://doi.org/ $10.3390 /$ su13158530

Academic Editor: Nyuk Hien Wong

Received: 17 June 2021

Accepted: 27 July 2021

Published: 30 July 2021

Publisher's Note: MDPI stays neutra with regard to jurisdictional claims in published maps and institutional affiliations.

Copyright: (c) 2021 by the authors. Licensee MDPI, Basel, Switzerland. This article is an open access article distributed under the terms and conditions of the Creative Commons Attribution (CC BY) license (https:/ / creativecommons.org/licenses/by/ $4.0 /)$.
Abstract: The rapid growth of urbanization and population has aggravated the urban heat island (UHI) effect in urban agglomerations. However, because scholars have so far focused mainly on the magnitude of the UHI effect, there is still a lack of research on the quantitative evaluation of the relationship between urban expansion and the degree of the UHI effect from the urban agglomeration perspective. This paper analyzed the spatiotemporal characteristics and the interactive mechanism of the surface urban heat island footprint (SUHI FP) in the Yangtze River Delta urban agglomeration (YRDUA). The summer footprints (FPs) of 27 cities were extracted using a logistics model, and the temporal trend was estimated by a standard deviation ellipse (SDE). Furthermore, the authors used the classical machine-learning k-means algorithm to cluster the temperature attenuation curves to reveal development patterns in different cities. The results showed that the degree of FP expansion during the daytime was more apparent than at night, the area of urban growth positively correlated with a city's population level, and from 2005 to 2018 (the period of the study), the spatial evolution for all cities showed an overall trend from east to west. These cities were divided roughly into three development patterns by clustering their 2018 temperature attenuation curves. These findings can provide a scientific basis for formulating effective land-use policies by giving a deeper understanding of the spatiotemporal changes in the SUHI FPs and their relationship with land cover in the YRDUA.

Keywords: urban heat island; footprint; logistics model; machine learning; attenuation curve; Yangtze River Delta urban agglomeration

\section{Introduction}

As urbanization accelerates, natural ground surfaces are made impervious by concrete and asphalt [1], which results in less urban evapotranspiration, enhanced absorption, and increased thermal radiation [2]. Under the combined influence of these factors, urban temperatures are significantly higher than in the surrounding rural areas, a phenomenon termed the "urban heat island" (UHI) effect [3], which brings with it many problems: deteriorating air quality [4], increased energy consumption [5], altered regional microclimates [6], and biodiversity loss [7]. Moreover, the UHI effect brings a greater risk of morbidity and mortality to the urban population [8]. It was first proposed in the 19th century and related research has increased since the 1960s with the London studies, and now it is a topic that has received attention in many fields [9-11].

Studies on UHIs are divided into two broad categories: atmospheric UHI (AUHI) and surface UHI (SUHI) [12]. The AUHI describes urban-rural differences in air temperature, 
including canopy and boundary layer UHIs [13]. The canopy layer UHI is usually measured using in situ sensors installed on fixed meteorological stations or vehicles [14,15]. The boundary layer UHI is measured from rooftops to the atmosphere and is commonly used to study the effect at a mesoscale (i.e., $1-10,000 \mathrm{~km}^{2}$ ) [16,17]. Nevertheless, the measured AUHI usually fails to provide sufficient spatial details for urban planning and climate change research due to the limitation of monitoring stations [18,19]. Research gaps in canopy and boundary layer UHIs are filled in by SUHIs, which measure the land surface temperature (LST) at the ground level [20]. Convenient access and continuous coverage of urban areas have prompted the SUHI to become the main topic of research into the heat island effect in recent decades [21,22].

Many types of indicators have been proposed to quantify the SUHI effect, of which the surface urban heat island intensity (SUHII) and surface heat island footprint (SUHI FP) are widely used indicators. SUHII is defined as the difference in LST between urban and surrounding reference areas and is mainly used to describe the magnitude of the SUHI effect $[23,24]$. Unlike SUHII, the SUHI FP quantitatively describes the area affected by SUHI by defining the degree of temperature rise relative to the rural reference area on a spatial scale [25-27]. Many scholars have used the FP to analyze the characteristics of spatiotemporal changes and associated factors of large cities or multiple cities [28]. For example, Anniballe revealed the seasonal variation of the FP in Milan by employing a Gaussian surface [29]. Santamouris estimated the FP of Athens, Greece, caused by the UHI phenomenon over the city [30]. Considering that the conclusions drawn from single-city research might be limited by local conditions, a few studies have attempted to investigate the FP of multiple cities. Tran concluded that there is a strong correlation between the population size and FPs of eight selected Asian megacities [31]. Yang estimated the FPs of 302 cities in China from 2003 to 2016 and systematically analyzed the temporal trend and the factors that affected it [32]. Though previous studies have greatly contributed to our understanding of FP spatial patterns and temporal trends, the relationship between FPs and city development has not been illustrated clearly.

In recent years, some scholars have discovered that urban agglomeration can cause great changes to the thermal environment of a large area [33]. Urban agglomeration is a large, multicore, multilevel grouping of metropolises having a number of centrally distributed megacities and large cities [34]. The UHI effect here is no longer a local phenomenon: the FP of a city in an urban agglomeration can overlap and interact with others, leading to more serious environmental problems. Large-scale observations and quantitative calculations on this have been conducted by remote sensing [34,35]; unfortunately, scholars paid too much attention to the relationship of the UHI intensity to human activity [36,37] and natural ecology [38]. They examined ecological indicators [39] and urban form and structure [40-42], but ignored the mechanism of FP interaction within the urban agglomeration.

The Yangtze River Delta urban agglomeration (YRDUA), one of the largest ones in China, experienced a significant development boom in recent decades $[43,44]$ which caused a significant change to its FP. Therefore, spatiotemporal analysis and machine learning were employed to mine the FP characteristics of cities with different UHI levels.

The main purpose of this research includes:

(1) To analyze the spatiotemporal changes and influences in the YRDUA FP from 2005 to 2018 .

(2) To explore the developmental characteristics of the cities according to FP temperature attenuation curves.

(3) To reveal the spatial overlay effect of the FP between the adjacent cities.

This research is designed to deepen our understanding of urban development and the mechanism of SUHIs to alleviate environmental problems caused by rapid urban development and provide a scientific foundation to formulate development planning for other urban agglomerations. The rest of the article is organized as follows. The methodology of the article, as well as the related data and its preprocessing, is introduced 
in Section 2. Then, the result and comparison analysis are illustrated in Section 3. The discussion follows in Section 4. Lastly, the conclusions and future work are in Section 5.

\section{Materials and Methods}

\subsection{Study Area}

The YRDUA, located in the lower reaches of the Yangtze River (Figure 1), is one of the most densely populated urbanized areas along China's southeast coast [45]. In addition, it has a pivotal strategic position in the overall pattern of China's national modernization. The outline for the integrated regional development of the Yangtze River Delta, jointly issued in 2019 by the Communist Party of China Central Committee and the State Council, stated that the YRDUA is composed of 1 megacity (Shanghai), 2 megalopolises (Nanjing, Hangzhou), and 24 other cities covering an area of $225,000 \mathrm{~km}^{2}$ [46]. The UHI effect in the YRDUA is aggravated by diverse land surfaces, a dense population, and a close interconnection among urban areas that threatens the health of residents, changes the regional thermal environment by raising the temperature in a continuous area, and thus impacts the ecological environment $[5,47]$.

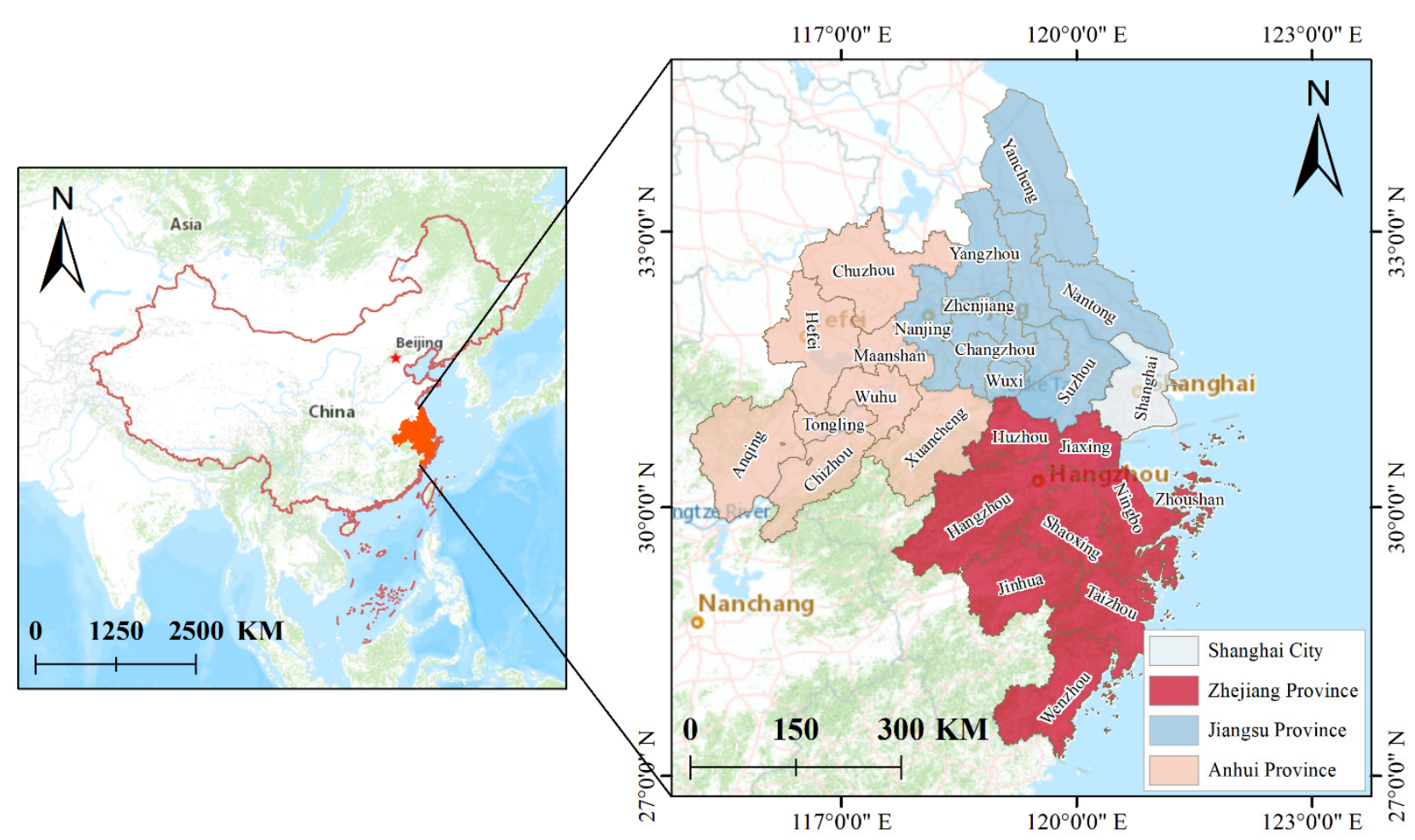

Figure 1. The location and administrative boundary of the YRDUA.

\subsection{Data}

As the moderate resolution imaging Spectroradiometer (MODIS) has a fine temporal resolution [26], the 8-day time series of $1 \mathrm{~km}$ MODIS LST product (MOD11A2) was selected as the temperature data source in this study. The MOD11A2 data were synthesized by the MOD11A1 product, which stored the average value of the surface temperature/emissivity under fine weather. The dataset over this period included daytime and nighttime surface temperatures and related data quality control information. The authors gained MOD11A2 data for 2005, 2010, 2015, and 2018 from NASA (https: / ladsweb.modaps.eosdis.nasa.gov/, accessed on 10 January 2021), and generated average summer daytime and nighttime LST data from June to August of each year. The data were converted from Kelvin to Celsius and used to calculate the SUHI FP of the YRDUA. 
The land-use data for 2005, 2010, 2015, and 2018 were derived from the Resource and Environment Data Cloud (RESDC) platform from the Chinese Academy of Science (http:/ / www.resdc.cn, accessed on 13 January 2021). The datasets included six primary classifications [40] (farmland, forest, grassland, water, build-up land, and unused land) with a spatial resolution of $30 \mathrm{~m}$. We chose the land-use data to extract the gravity center of the built-up areas, to eliminate the effect of water on SUHI FP calculations, and to analyze the impact of different land types on the SUHI FP.

Digital elevation model (DEM) data with a spatial resolution of about $90 \mathrm{~m}$ were obtained from the Geospatial Data Cloud (http:/ / www.gscloud.cn, accessed on 11 January 2021) and employed to eliminate the effect of terrain on LST.

Population data were collected from the China Statistical Yearbook (http:/ /www. mohurd.gov.cn, accessed on 13 January 2021), issued by the National Bureau of Statistics, and the statistical yearbooks of each city. All the data and their descriptions are shown in Table 1.

Table 1. The data source list.

\begin{tabular}{cccc}
\hline Data & Resolution & Year & URL \\
\hline MOD11A2 & $1 \mathrm{~km}$ & $2005,2010,2015$, and 2018 & https://ladsweb.modaps.eosdis.nasa.gov/ \\
Land-use data & $30 \mathrm{~m}$ & 2005, 2010, 2015, and 2018 & http://www.resdc.cn \\
hEM & $90 \mathrm{~m}$ & \multicolumn{1}{c}{ http://www.gscloud.cn } \\
Population data & $\backslash$ & 2005, 2010, 2015, and 2018 & http://www.mohurd.gov.cn \\
\hline
\end{tabular}

The development level of the YRDUA cities was quite varied due to geographical, historical, and policy factors [32,40]. To determine the FP characteristics the 27 cities were divided by population into three levels (Table 2): Level $1(>1,000,000)$, Level 2 $(500,000-1,000,000)$, and Level $3(<500,000)$.

Table 2. City levels in the YRDUA.

\begin{tabular}{|c|c|}
\hline City Level & City Name \\
\hline Level 1 & $\begin{array}{c}\text { Shanghai, Nanjing, Hangzhou, Suzhou, Hefei, Wuxi, Ningbo, Changzhou, Wenzhou, } \\
\text { Yancheng, Nantong, Wuhu, Yangzhou, Taizhou (ZJ) }\end{array}$ \\
\hline Level 2 & Shaoxing, Taizhou (JS), Zhenjiang, Jinhua, Anqing, Ma'anshan, Huzhou, Zhoushan, Jiaxing \\
\hline Level 3 & Tongling, Chuzhou, Chizhou, Xuancheng \\
\hline
\end{tabular}

Note: JS: Jiangsu Province; ZJ: Zhejiang Province.

\subsection{Method}

For this study, a systemic analysis of the FP in the YRDUA was conducted and consisted of four parts (Figure 2): the FP calculation, spatiotemporal characteristics analysis of the FP, clustering of temperature attenuation curves, and the determination of the overlay effect.

Based on the derived data, the summer FPs of each city in four-slice epoch coverage of $2005,2010,2015$, and 2018 were firstly calculated based on the temperature curve fitting and logistical model. The heterogeneity and evolution about FP of 27 cities in YRD were then shown via the attenuation curve graphs. The shape feature of the temperature attenuation curve is used to cluster the TAC curve. Finally, the mutual influence phenomenon which occurred in the adjacent cities due to the development of urban agglomeration to a certain stage was introduced.

\subsubsection{Calculation of the SUHI FP}

The logistics model was used to calculate the boundary of the FP by setting the LST threshold of the reference rural area in all directions [26]. It is more accurate than the single exponential decay [28] and Gaussian surface models [48-50] because it minimizes the effects of a city's shape, topography, or landscape heterogeneity. It consists of four steps. 


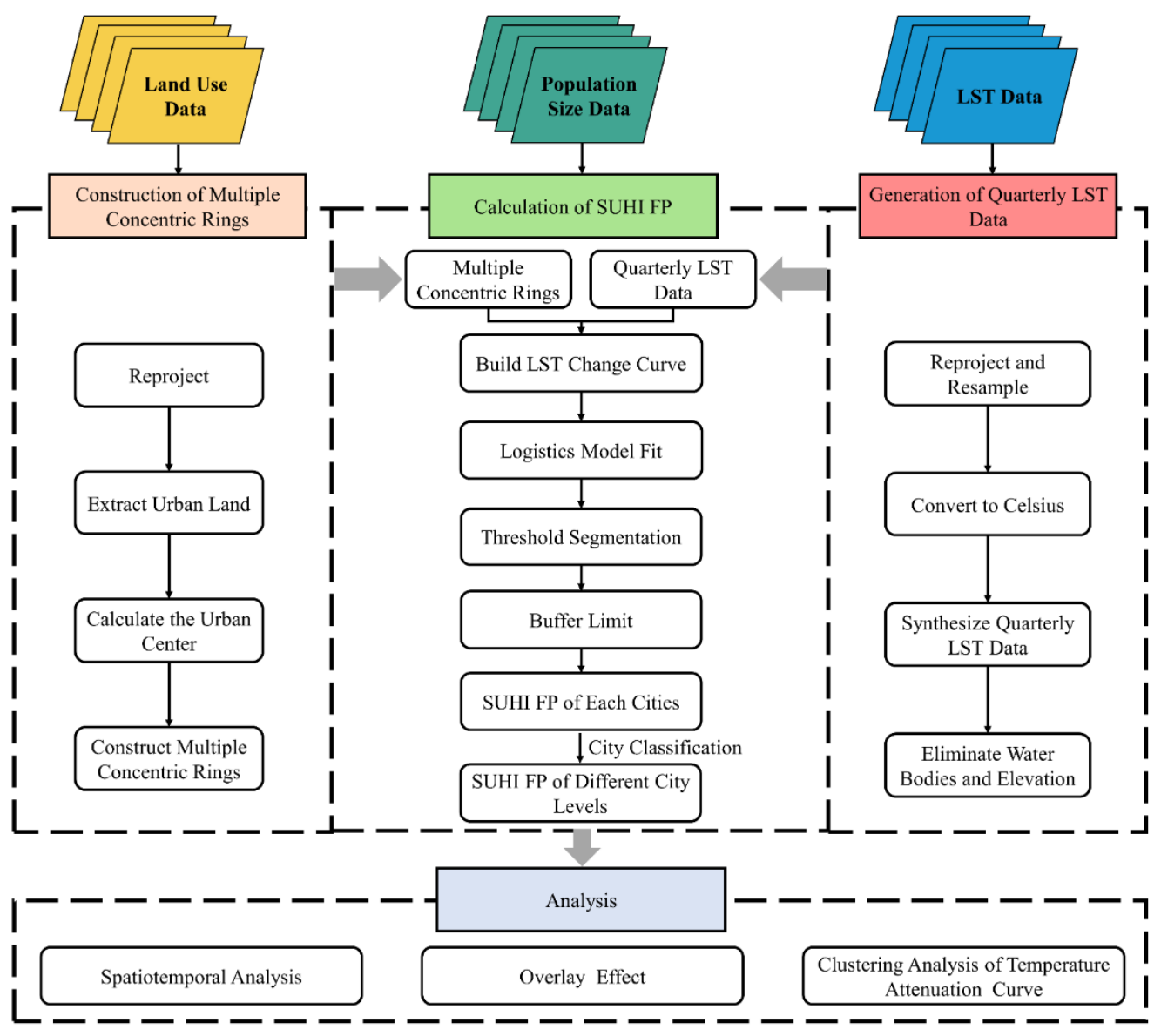

Figure 2. The framework of the study.

Step 1: The main urban land in the city is selected. To reduce deviation in the FP calculation, temperature pixels in bodies of water and land outside the average elevation of $\pm 50 \mathrm{~m}$ [32] are excluded. Rural background reference points for different directions are then assumed, and the city center is set as the origin of the polar coordinates. The LST of each pixel in any direction and the reference rural LST can be expressed as $T_{\text {pixel }}(\theta, r), T_{r e f}(\theta, r)$, where the $r$ is the radius and $\theta$ denotes the radian measure of the central angle.

Step 2: Multiple concentric rings of equal area are drawn from the urban center to the surrounding rural areas with the initial radius set to $5 \mathrm{~km}$. To ensure that each subsequent ring has an equal area, the radius of each was $5 \sqrt{i} \mathrm{~km}$, where $i$ is the number of concentric rings. The average LST of each ring $\left(\overline{T_{S}}(r)\right)$ can be calculated using Equation (1). The blue dots in Figure 3 represent the average LST values for each concentric ring.

$$
\overline{T_{S}}(r)=\frac{1}{2 \pi} \int_{0}^{2 \pi} T_{\text {pixel }}(\theta, r) d \theta
$$

Step 3: Using the logistics model, a curve is fitted on a graph with the $x$ axis as the number of concentric rings and the $y$ axis as $\overline{T_{S}}(r)$. The curvature $(K)$ (red line) and its rate of change $\left(K^{\prime}\right)$ (dotted black line) for each ring (Figure 3) can be calculated by the following equations:

$$
\begin{gathered}
K=\frac{d_{\beta}}{d_{s}}=-\frac{b^{2} c z(1-z)(1+z)^{3}}{\left((1+z)^{4}+(b c z)^{2}\right)^{3 / 2}} \\
K^{\prime}=b^{3} c z\left(\frac{3 z(1-z)(1+z)^{3}\left(2(1+z)^{3}+b^{2} c^{2} z\right)}{\left((1+z)^{4}+(b c z)^{2}\right)^{5 / 2}}-\frac{(1+z)^{2}\left(1+2 z-5 z^{2}\right)}{\left((1+z)^{4}+(b c z)^{2}\right)^{3 / 2}}\right)
\end{gathered}
$$


where $z=e^{a+b r} ; a$ and $b$ are the parameters of the logical curve to be fitted; the sum of $c$ and $d$ is the highest average LST value among the concentric circles; $d$ is the lowest average temperature LST value among the concentric circles; $\beta$ is the angle of the unit tangent vector at the buffer ring $r$ along the differentiable curve; $s$ is the unit length of the curve.

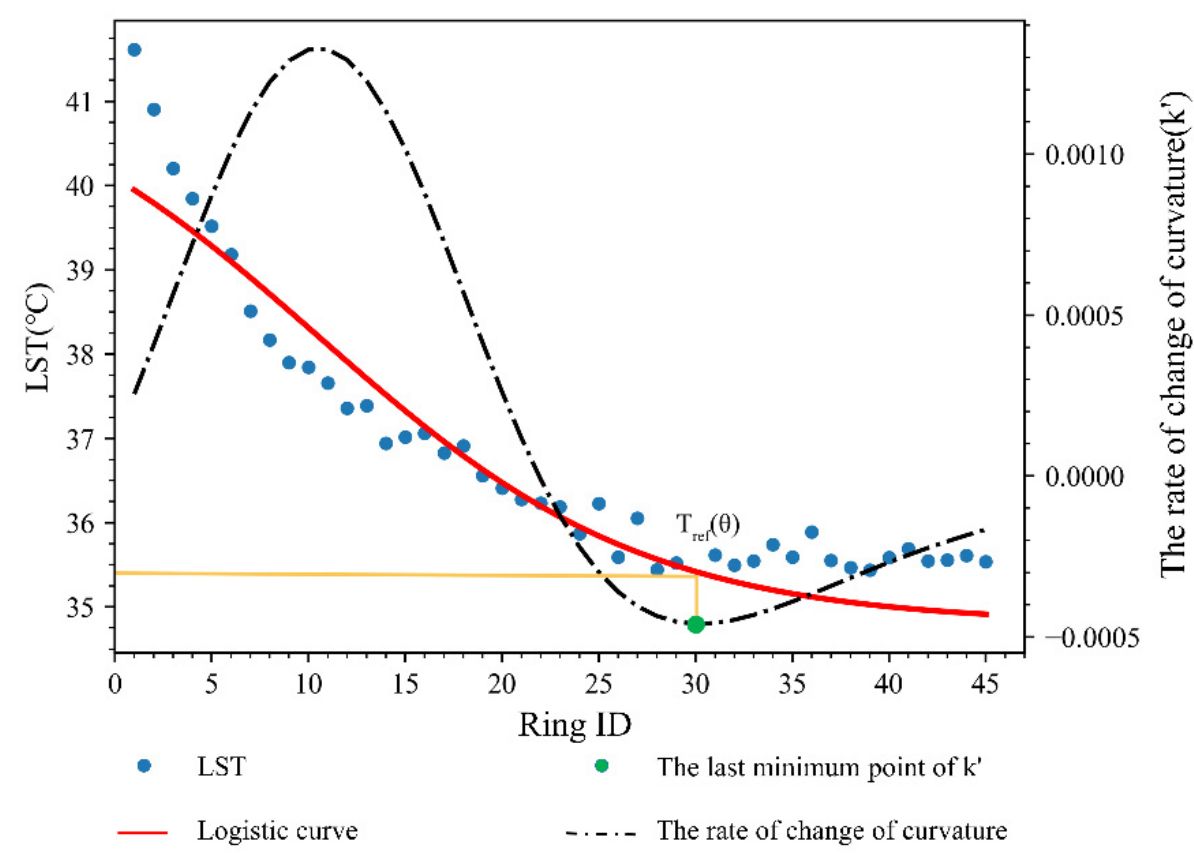

Figure 3. Schematic diagram showing how to employ the logistics model to calculate $T_{\text {ref }}(\theta)$ (Suzhou, 2005, summer daytime).

Step 4: The fitted LST value corresponding to the last minimum point of $K^{\prime}$ is defined as the reference rural LST value $\left(T_{r e f}(\theta)\right)$ for the angle $\theta$, and pixels with a value greater than $T_{r e f}(\theta)$ (green point in Figure 3) are classified into the SUHI FP. If the last minimum point of $K^{\prime}$ does not exist, the initial radius is reduced by $1 \mathrm{~km}$ intervals and Steps $2-4$ are repeated.

\subsubsection{Standard Deviational Ellipse (SDE)}

SDE is a classic method in spatial statistical methods [49], which is widely used in spatial distribution and evolution of geographic elements [31,50-52]. This experiment used SDE to analyze the spatial distribution characteristics of the SUHI FP of the YRDUA, including the area, center of gravity, and direction of the ellipse. The elements of SDE are expressed as follows:

$$
\begin{gathered}
S D E_{x}=\sqrt{\frac{\sum_{i=1}^{n}\left(x_{i}-\bar{X}\right)}{n}} \\
S D E_{y}=\sqrt{\frac{\sum_{i=1}^{n}\left(y_{i}-\bar{Y}\right)}{n}} \\
\tan \alpha=\frac{\left(\sum_{i=1}^{n} \bar{x}_{i}^{2}-\sum_{i=1}^{n} \bar{y}_{i}^{2}\right)+\sqrt{\left(\sum_{i=1}^{n}{\overline{x_{i}}}^{2}-\sum_{i=1}^{n}{\overline{y_{i}}}^{2}\right)^{2}+4\left(\sum_{i=1}^{n} \overline{x_{i}} \overline{y_{i}}\right)^{2}}}{2 \sum_{i=1}^{n} \overline{x_{i}} \overline{y_{i}}} \\
\sigma_{x}=\sqrt{2} \sqrt{\frac{\sum_{i=1}^{n}\left(\overline{x_{i}} \cos \alpha-\overline{y_{i}} \sin \alpha\right)^{2}}{n}} \\
\sigma_{y}=\sqrt{2} \sqrt{\frac{\sum_{i=1}^{n}\left(\overline{x_{i}} \sin \alpha-\overline{y_{i}} \cos \alpha\right)^{2}}{n}}
\end{gathered}
$$


where $\left(S D E_{x}, S D E_{y}\right)$ are the centroid of the ellipse, $\left(x_{i}, y_{i}\right)$ are the geographic coordinates of the $i$ th SUHI FP pixel, $(\bar{X}, \bar{Y})$ are the arithmetic mean center, and $\left(\overline{x_{i}}, \overline{y_{i}}\right)$ are the difference between the mean center and coordinates of $X Y . \sigma_{x}$ is the length of the long axis of the ellipse, and $\sigma_{y}$ is the short axis of the ellipse. The angle $\alpha$ represents the ellipse directional orientation, indicating the clockwise rotation degree from north to the ellipse long axis.

\subsubsection{Clustering of UHI Attenuation Curve}

Clustering analysis, an important branch in the field of machine learning, is an unsupervised learning method that can reveal the inherent properties and laws of data through the learning of untagged training samples. This paper drew the temperature attenuation curve within the circle of the FP using the k-means algorithm to explore the relationship between temperature attenuation and the stage of urban development. The specific process followed three steps:

Step 1: Each city's temperature attenuation curve was plotted. After the smallest FPbased circle was drawn, 30 equal-area rings were generated, and the average temperature processed by a minimum-maximum normalization for each ring was extracted.

Step 2: The characteristic indexes of the attenuation curve were extracted. The variance (Var), coefficient of variation (CV), and sum of adjacent points' slopes (SAPS) were used to estimate the volatility of different curves. Their formulas are as follows:

$$
\begin{gathered}
\text { Var }=\frac{\sum_{i=1}^{N}\left(x_{i}-\frac{x_{1}+x_{2}+x_{3}+\cdots+x_{N}}{N}\right)^{2}}{N} \\
C V=\frac{\sqrt{\frac{\sum_{i=1}^{N}\left(x_{i}-\frac{x_{1}+x_{2}+x_{3}+\cdots+x_{N}}{N}\right)^{2}}{N}}}{\frac{x_{1}+x_{2}+x_{3}+\cdots+x_{N}}{N}} \\
\text { SAPS }=\sum_{i=2}^{N}\left|\frac{\left(x_{i}-x_{i-1}\right)}{\Delta x}\right|
\end{gathered}
$$

where $N$ refers to the length of the curve sequence (30 in this experiment); $x_{i}$ refers to the average temperature corresponding to the $i$ th circle in the sequence; $\Delta x$ refers to the increment of two adjacent points on the $x$-axis.

Step 3: The FP attenuation curve was clustered using the k-means algorithm, which uses Euclidean distance as a measure of similarity among data objects and to minimize differences in the same cluster. $\mathrm{K}$ was set at 3 according to the level of a city's population.

\section{Result}

\subsection{The Results of SUHI FP}

The logistics model was employed to fit the LST change curve of each city in summer and calculated the $T_{r e f}(\theta)$ to determine the FP (Figure 4). Figure 5 shows the results of the FP of typical cities in the three levels. The FPs of Heifei, Jiaxing, and Xuancheng reached 7, 5 , and 11 times the urban land area, respectively, and the proportions of paddy fields in the FPs were 63,56 , and $48 \%$, respectively. Furthermore, the $T_{r e f}(\theta)$ determined by the main urban land could not be used to calculate the FP of other urban land areas if the logistics model was applied to a city that had multiple urban land centers.

Hence, the paper referred to previous studies $[25,26,28,32]$ to use the FP of a main urban land to represent the FP of an entire city and employed concentric rings to constrain the FP to reduce the impact of bare land. Pixels having a value greater than the $T_{r e f}(\theta)$ were first classified as the FP, and then concentric rings with an average LST higher than the $T_{r e f}(\theta)$ were used to make constraints when calculating the FP. The final results of the FPs of typical cities in the three city levels are shown in Figure 6. 

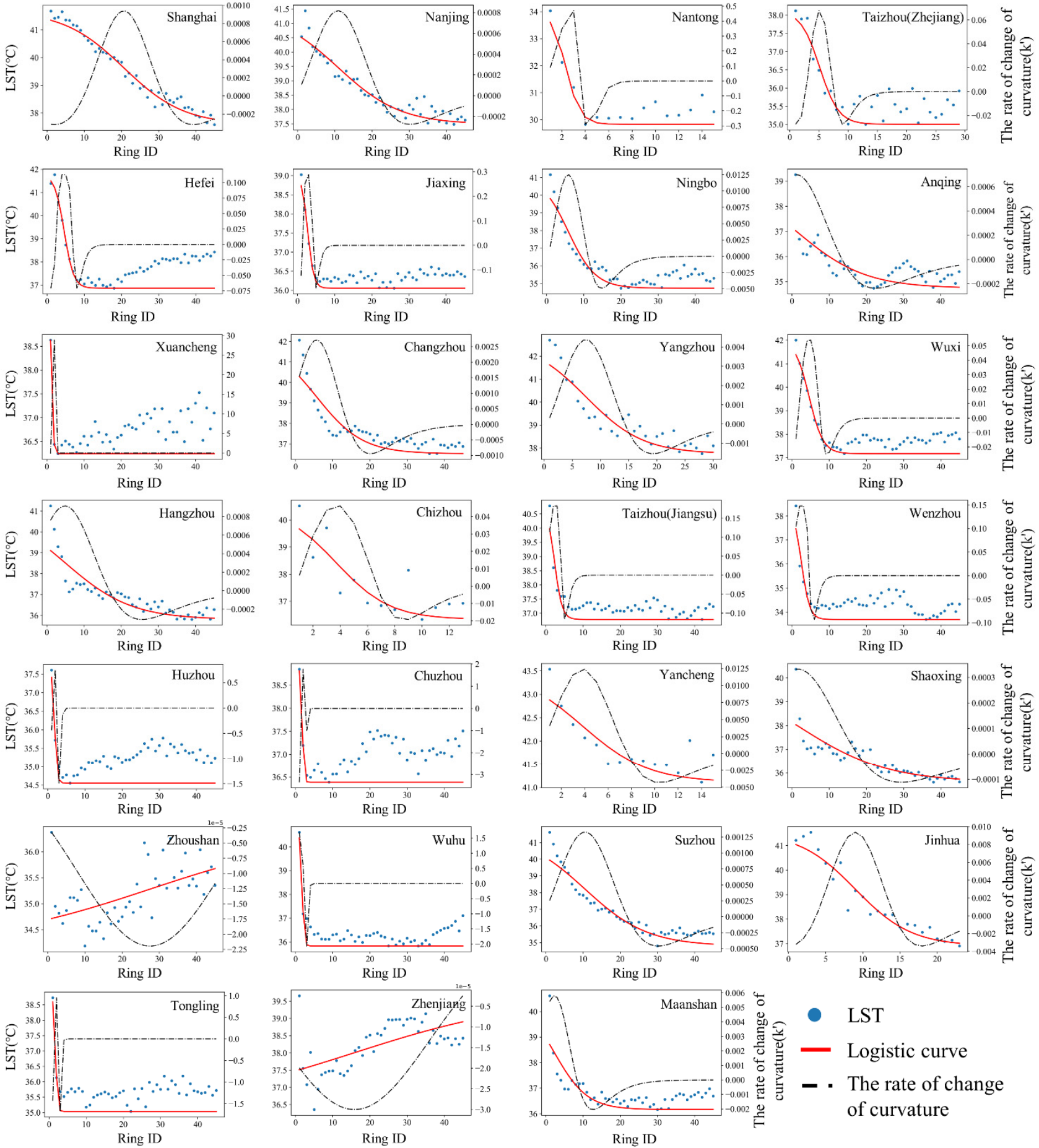

Figure 4. The fitting curve of 27 cities in the summer daytime of 2005.

\subsection{Spatiotemporal Changes of SUHI FP}

The total area of the FP was proportional to the city level and generally showed an upward trend that was higher during the daytime. Figure 7 illustrates the areas of different city levels (day and night) from 2005 to 2018. During the daytime, the SUHI FP area of both Level 1 and Level 3 cities increased gradually, but the growth rate of Level 1 cities was relatively stable and had a small value. However, the growth rate of Level 3 cities increased sharply from 2005 to 2010, but dropped to the same level as that of Level 1 cities from 2015 to 2018. In short, Level 1 cities showed steady expansion while Level 3 cities experienced large-scale expansion from 2005 to 2010, but weak expansion in the following years until 
it leveled off. This phenomenon indicated that the strategy of promoting urbanization changed from rapid development to high-quality development. The SUHI FP area of Level 2 cities first decreased and then increased, and the growth rate of this region turned from negative to positive. During the nighttime, both the SUHI FP area and growth rate of Level 1 and Level 2 cities continued to rise. Level 3 cities first had experienced an upward trend and then a decline; meanwhile, the growth rate of this region continued to fall.

Moreover, the area of the YRDUA FP showed an overall spatial expansion trend from east to west during both daytime and nighttime, as shown in Figure 8 and Table 3. In the daytime, the center of gravity of the FPs first moved to the northwest and then to the southeast, but the overall direction of movement was northwest. From 2010 to 2015, the movement was the most obvious: 23,257.1 m northwest from Suzhou to Huzhou. In the nighttime, the gravity center of the FP first moved southwest, then turned northeast, and finally northwest. Although the moving directions were different for the three times, it moved southwest overall. The most obvious period for movement was from 2005 to 2010, with a maximum movement of $49,089.05 \mathrm{~m}$.
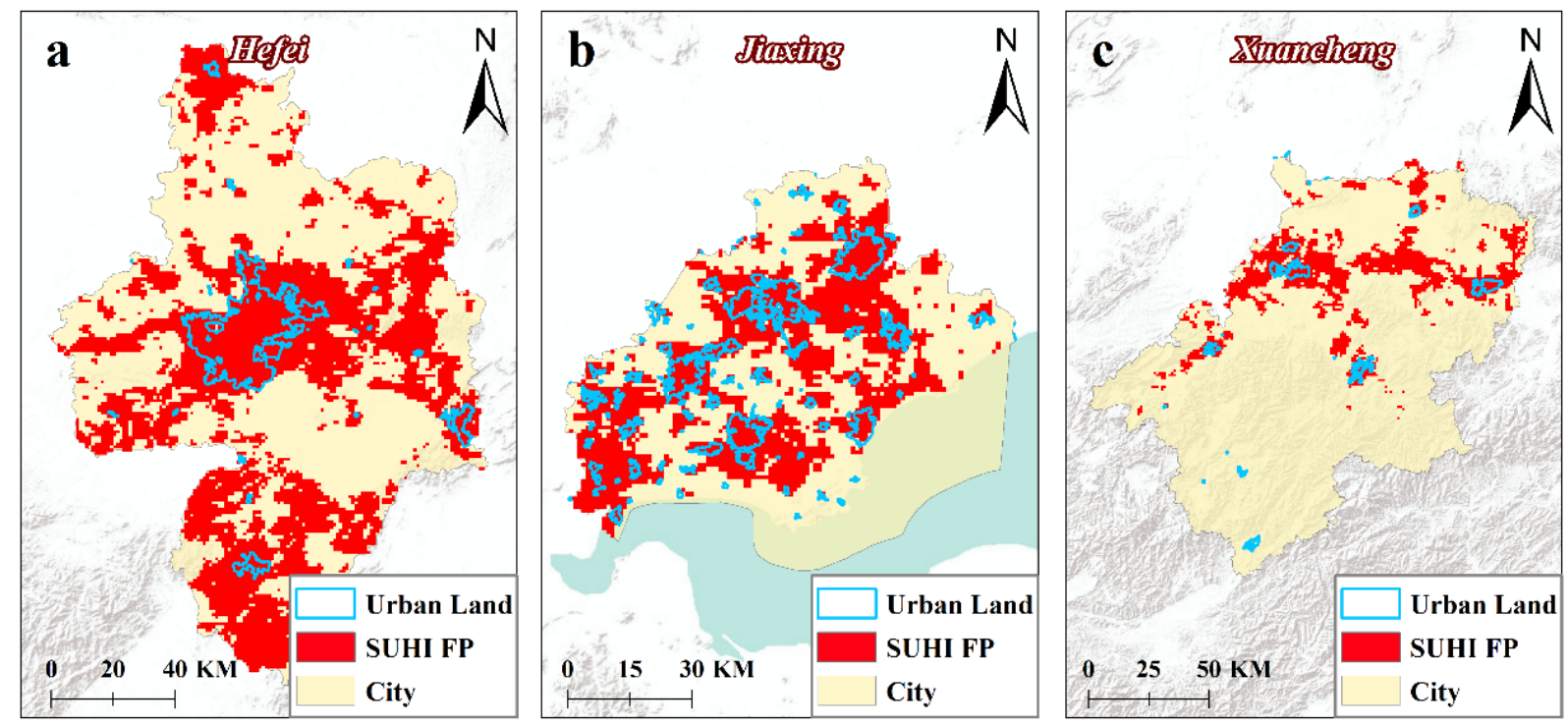

Figure 5. The FPs of typical cities in three levels of cities in 2018 summer daytime. (a) Heifei (Level 1), (b) Jiaxing (Level 2), (c) Xuancheng (Level 3).

There was a large difference between the length of the major axis and the minor axis of the ellipse, which proved that the FP distribution was directional. From 2005 to 2018, the length of the major axis in the daytime increased, which indicated that the FP expanded in the northeast-southwest (major axis) direction, whereas the FP contracted in the major axis direction at nighttime because the length of the major axis decreased. In the daytime, the area of the SDE increased by $46,076.29 \mathrm{~km}^{2}$, with a growth rate of $10.723 \%$. At night, the SDE increased by $19,166.97 \mathrm{~km}^{2}$, with a growth rate of $3.762 \%$, indicating that the expansion of the FP was more obvious in the daytime.

\subsection{The Correlation between SUHI FP and Urban Development}

To discover the correlation between the FP and urban development, the k-means algorithm was used to cluster the temperature attenuation curves. All the 2018 curves were of three types: high volatility, medium volatility, and low volatility, as shown in Figure 9. According to their shape characteristics, the patterns of urban development for the 27 cities were obtained. Cities with low-volatility curves showed that urban construction had certain advantages and presented balanced development in all directions. High-volatility curves presented the obvious directional differences in the urban development pattern. The main reason was that these cities were mostly undergoing rapid development and intensified human production, as a result of which living activities in local areas aggravated 
the spatial imbalance in the construction of the built-up area. Moreover, some cities had moderate curve fluctuations because urban development was not as advanced. Therefore, the influence of SUHI on these cities was not particularly strong.
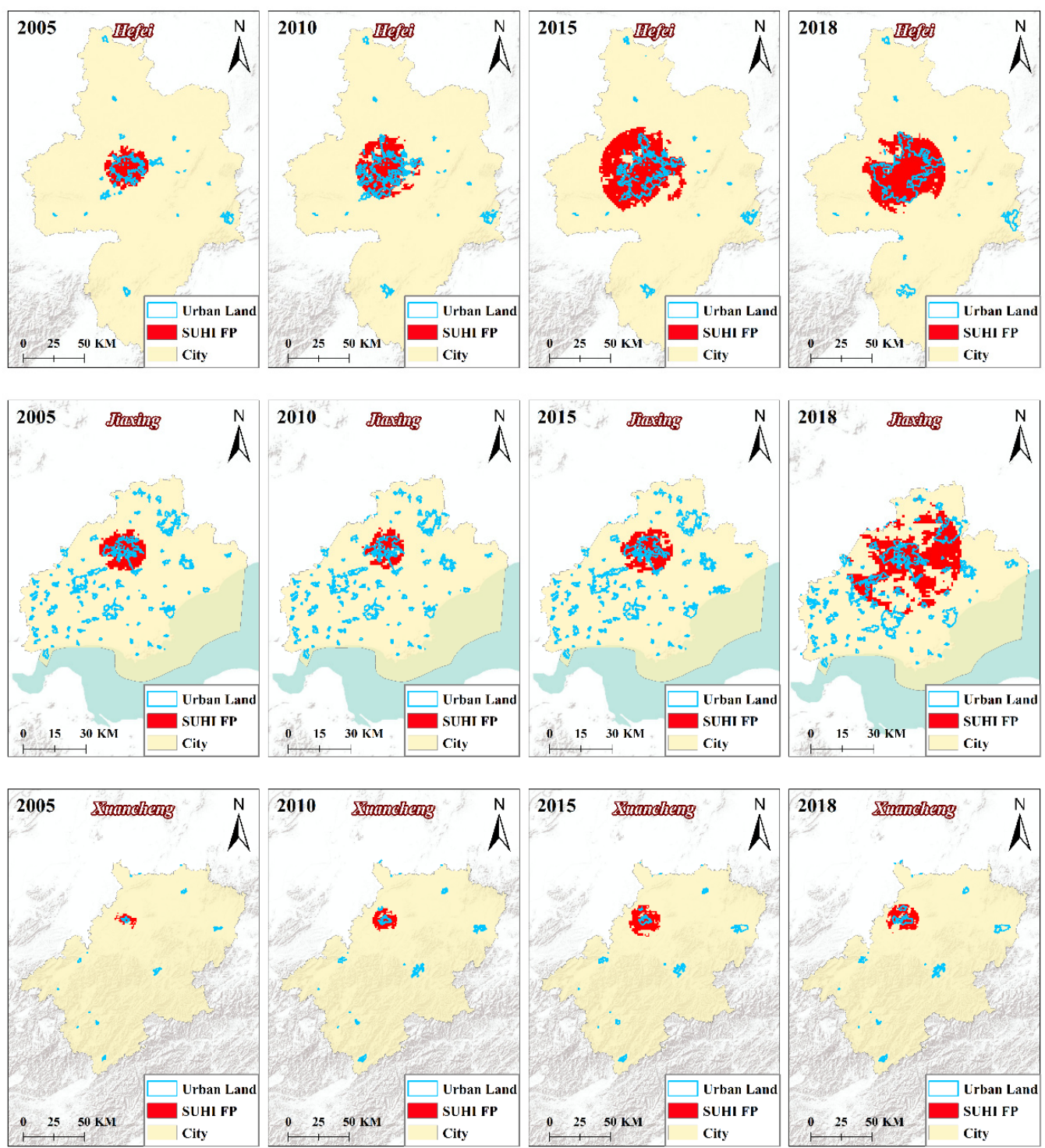

Figure 6. The final FPs of typical cities in three city levels in the daytime from 2005 to 2018.
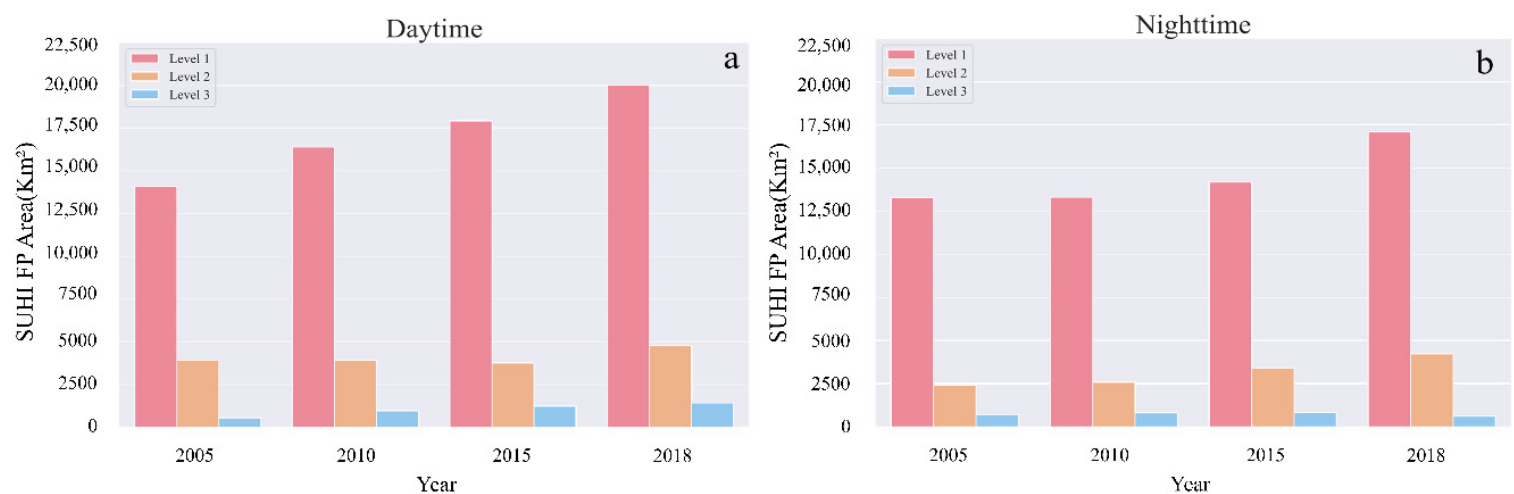

Figure 7. The area changes in FP during the daytime and nighttime in the summer from 2005 to 2018. (a) The area changes of FP in the daytime; (b) the area changes of FP in nighttime. 

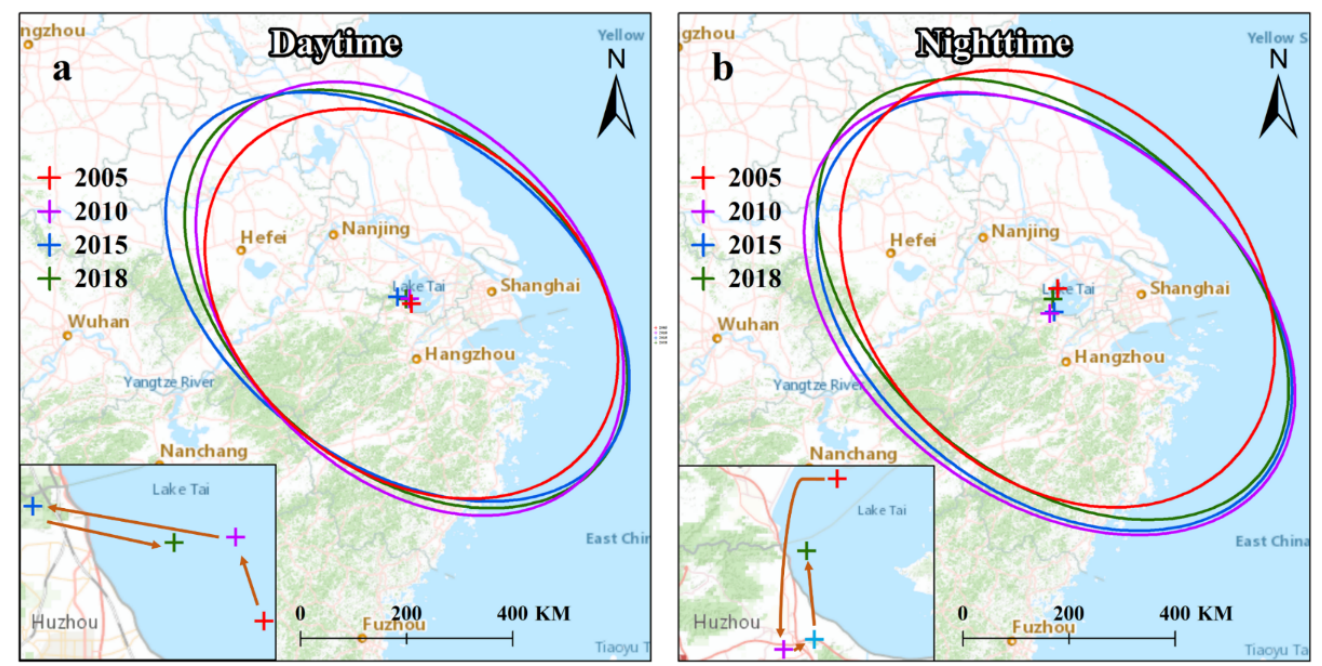

Figure 8. Changes in the distribution center of the FP. (a) Daytime; (b) nighttime.

Table 3. Parameters of standard deviation ellipse.

\begin{tabular}{cccccccc}
\hline Time & Year & $\begin{array}{c}\text { Standard } \\
\text { Deviation } \\
\text { Ellipse } \\
\text { Range }\left(\mathbf{k m}^{2}\right)\end{array}$ & $\begin{array}{c}\text { Major Axis } \\
\mathbf{( m )}\end{array}$ & $\begin{array}{c}\text { Minor Axis } \\
\mathbf{( m )}\end{array}$ & $\begin{array}{c}\text { Center of Gravity } \\
\text { Coordinates }\end{array}$ & $\begin{array}{c}\text { Center of } \\
\text { Gravity } \\
\text { Moving } \\
\text { Distance (m) }\end{array}$ & $\begin{array}{c}\text { Direction of } \\
\text { Movement }\end{array}$ \\
\hline \multirow{6}{*}{ Day } & 2005 & $429,703.01$ & $429,346.17$ & $318,592.84$ & $\left(120^{\circ} 07^{\prime} \mathrm{E}, 31^{\circ} 01^{\prime} \mathrm{N}\right)$ & \\
& 2010 & $485,163.19$ & $469,885.70$ & $328,679.17$ & $\left(120^{\circ} 06^{\prime} \mathrm{E}, 31^{\circ} 05^{\prime} \mathrm{N}\right)$ & $10,044.24$ & northwest \\
& 2015 & $482,801.36$ & $490,496.55$ & $313,337.07$ & $\left(119^{\circ} 53^{\prime} \mathrm{E}, 31^{\circ} 07^{\prime} \mathrm{N}\right)$ & $23,257.10$ & northwest \\
& 2018 & $475,779.29$ & $477,480.21$ & $317,196.35$ & $\left(120^{\circ} 02^{\prime} \mathrm{E}, 31^{\circ} 05^{\prime} \mathrm{N}\right)$ & $16,559.18$ & southeast \\
\hline \multirow{6}{*}{ Night } & 2005 & $509,465.55$ & $3,650,919.71$ & $461,815.62$ & $\left(120^{\circ} 03^{\prime} \mathrm{E}, 31^{\circ} 16^{\prime} \mathrm{N}\right)$ & \\
& 2010 & $563,916.79$ & $515,661.74$ & $348,118.94$ & $\left(119^{\circ} 56^{\prime} \mathrm{E}, 30^{\circ} 54^{\prime} \mathrm{N}\right)$ & $49,089.05$ & southwest \\
& 2015 & $540,783.54$ & $502,414.05$ & $342,640.69$ & $\left(120^{\circ} 00^{\prime} \mathrm{E}, 30^{\circ} 55^{\prime} \mathrm{N}\right)$ & 8815.38 & northeast \\
& 2018 & $528,632.51$ & $510,257.64$ & $32,9794.37$ & $\left(119^{\circ} 59^{\prime} \mathrm{E}, 31^{\circ} 07^{\prime} \mathrm{N}\right)$ & $24,417.73$ & northwest \\
\hline
\end{tabular}

It can be seen from Table 4 that the clustering results of the temperature attenuation curves corresponded strongly with population size, indicating that the shapes of the curves had great reference significance for urban patterns. However, the matching results of a few cities, such as Shanghai, were different because they were affected by spatial location, which resulted in abnormal curves. The experimental results show that the shape of the temperature attenuation curve can reflect the development stage of the urban heat island to a certain extent. So we suppose that this curve can be considered as a "fingerprint" for the development stage identification of the urban heat island. However, there are still some outlier cities, which shows that this work still has a lot of room for improvement, including the method selection of clustering, the elimination of the urban shape affection, calculation of the standard curve, et al.

\subsection{Overlay Effect of SUHI FP}

The continuous expansion of the city led to the narrowing of the gap between cities and even the connection among adjacent urban areas, resulting in an FP several times the area of the city [25]. In theory, when one urban area of a city is close to urban areas of other cities, there is an overlay or connection of FPs. To verify this phenomenon, the authors drew a straight line between the gaps in the urban areas of Wuxi and Changzhou during the summer daytime LST in 2018 and constructed an LST curve on it (Figure 10a). In general, the LST in the adjacent suburbs should have been lower and more stable than that of the urban land areas. However, the LST curve between the urban land areas in Wuxi and Changzhou showed that the LST between them (red line in Figure 10b) was 
higher compared with the temperature at the start and end points. Moreover, the LST curve which passes through the urban land areas of Changzhou and Wuxi illustrated that the temperature in the middle of the two urban land areas (red line in Figure 10d) was significantly higher than the temperature at both ends of the section line (green line in Figure 10d). Noticeably, the ends of the section line were in the non-urban land area and were not affected by the urban land areas of other cities. Obviously, the cause of this phenomenon is the overlay of the Wuxi and Changzhou FPs.
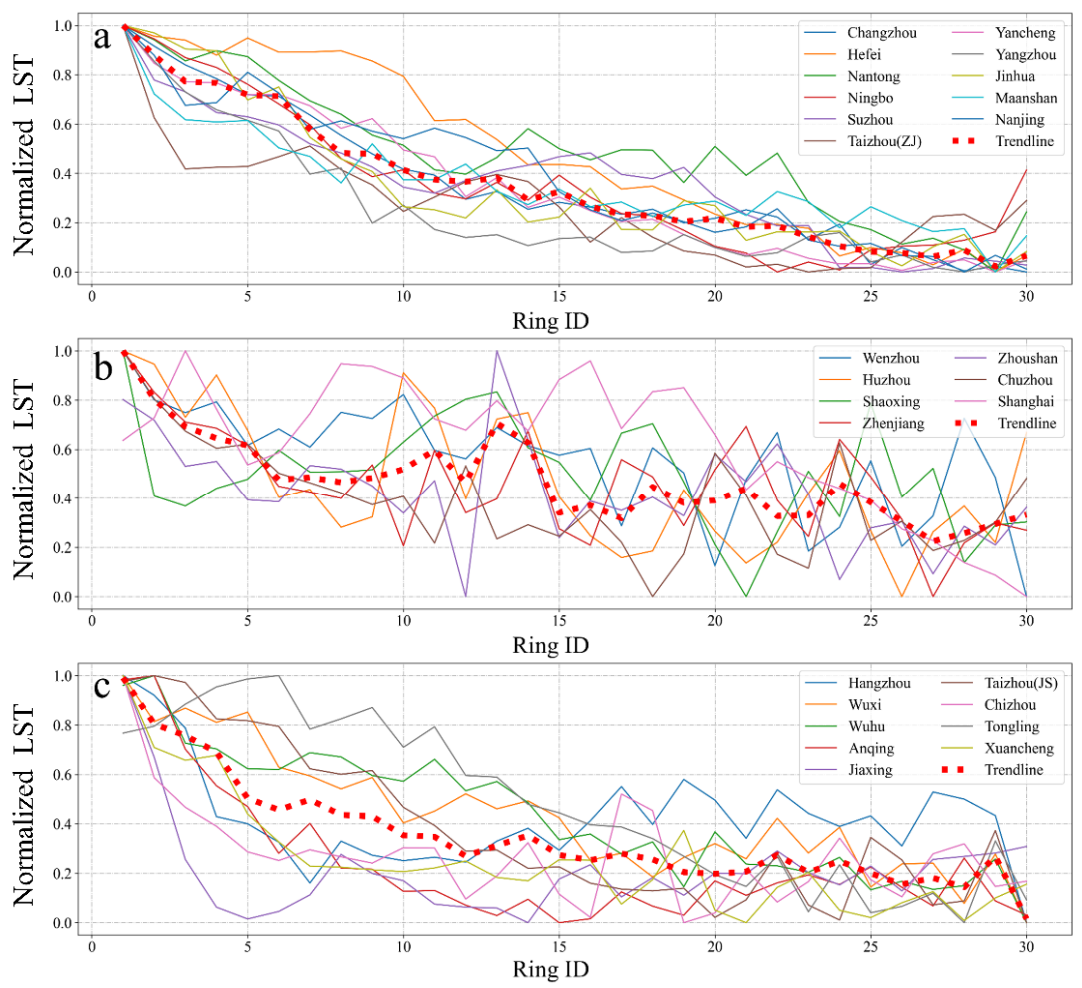

Figure 9. Clustering results of temperature attenuation curves. (a) Low-volatility curves; (b) highvolatility curves; (c) medium-volatility curves.

Table 4. Population size and development status of different cities. For population, 1, 2, and 3 represent large cities, medium cities, and small cities, respectively. In the clustering category, 1, 2, and 3 represent a low-volatility curve, high-volatility curve, and medium-volatility curve, respectively.

\begin{tabular}{|c|c|c|c|c|c|}
\hline City & $\begin{array}{l}\text { Population Size } \\
\text { Category }\end{array}$ & $\begin{array}{l}\text { Clustering } \\
\text { Category }\end{array}$ & City & $\begin{array}{c}\text { Population Size } \\
\text { Category }\end{array}$ & $\begin{array}{c}\text { Clustering } \\
\text { Category }\end{array}$ \\
\hline Changzhou & 1 & 1 & Anqing & 2 & 3 \\
\hline Hangzhou & 1 & 3 & Huzhou & 2 & 2 \\
\hline Hefei & 1 & 1 & Jiaxing & 2 & 3 \\
\hline Nanjing & 1 & 1 & Jinhua & 2 & 1 \\
\hline Nantong & 1 & 1 & Ma'anshan & 2 & 1 \\
\hline Ningbo & 1 & 1 & Shaoxing & 2 & 2 \\
\hline Shanghai & 1 & 3 & Taizhou (JS) & 2 & 3 \\
\hline Suzhou & 1 & 1 & Zhenjiang & 2 & 2 \\
\hline Taizhou (ZJ) & 1 & 1 & Zhoushan & 2 & 2 \\
\hline Wenzhou & 1 & 2 & Chizhou & 3 & 3 \\
\hline Wuxi & 1 & 3 & Chuzhou & 3 & 2 \\
\hline Wuhu & 1 & 3 & Tongling & 3 & 3 \\
\hline Yancheng & 1 & 1 & Xuancheng & 3 & 3 \\
\hline Yangzhou & 1 & 1 & & & \\
\hline
\end{tabular}



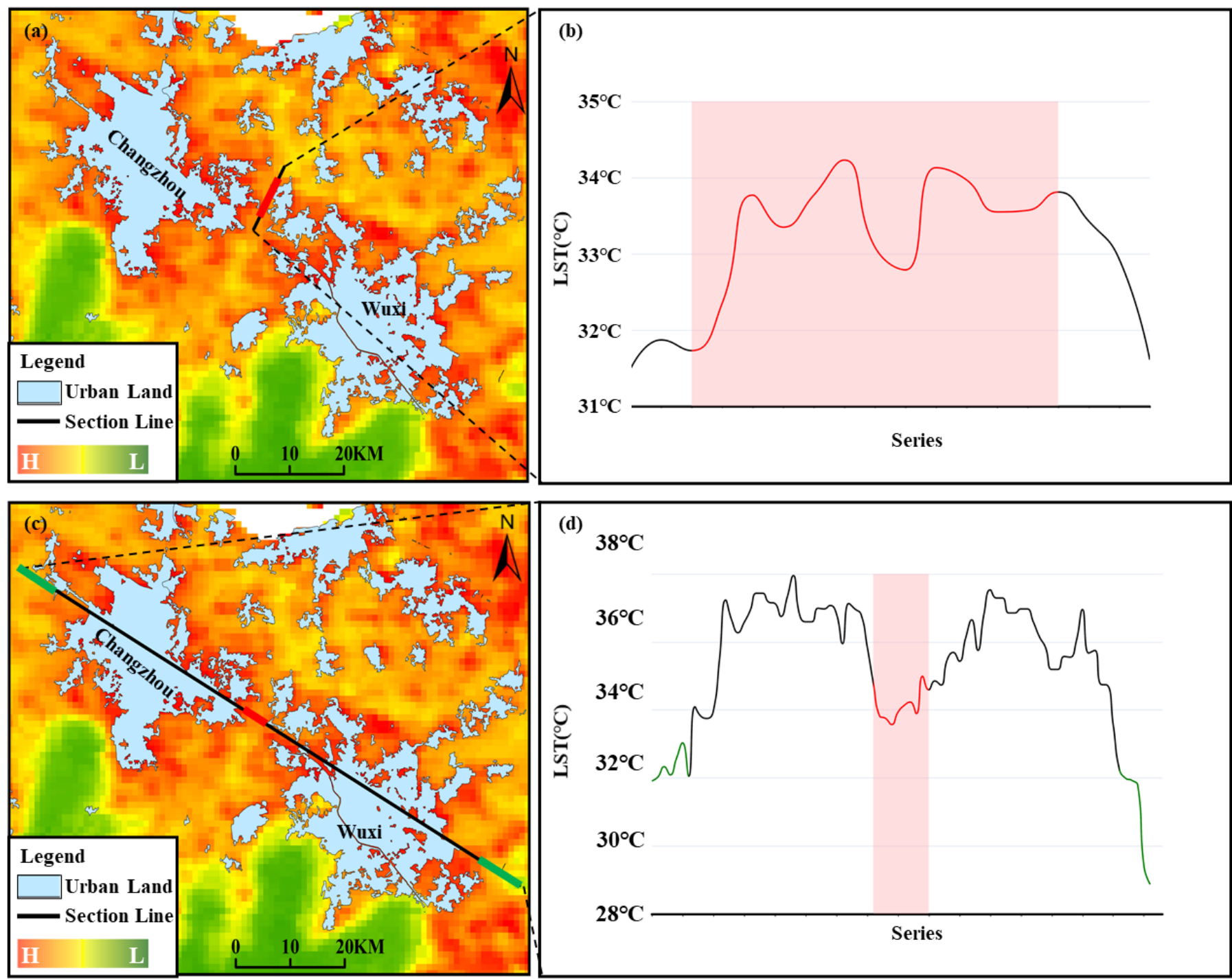

Figure 10. LST change curve in the urban land of Wuxi and Changzhou. (a) Schematic diagram of section line; (b) LST change curve on the section line in picture (a). (c) Schematic diagram of section line; (d) LST change curve on the section line in picture (c). The section line in picture (a) was drawn between the gap in the urban land of Wuxi and Changzhou, and the section line in picture (c) passed through the urban land areas of Wuxi and Changzhou. The red line of the LST curve in picture (b) represents the LST rise caused by the superposition effect of SUHI FP. The red and green lines on the LST curve correspond to the temperature of the red and green lines on the section line, respectively.

As the overlay of FPs is inevitable, the effect intensifies the impact on the suburbs around urban agglomerations, and even causes the LST to rise in large contiguous areas, leading to more serious environmental problems. Therefore, the overlay effect of the FP should not be ignored.

\section{Discussion}

\subsection{Relationship between SUHI FP and Land Use}

The conversion of different land-use types seriously affects the LST model and the scale of the UHI effect [53,54]. The proportion of six land-use types within the FP at different city levels is shown in Table 5. The built-up area and farmland are the main components of the SUHI FP in all three city levels. For example, the largest proportion of built-up land in Level 2 cities is $60.20 \%$, while the corresponding proportion of farmland is $22.30 \%$. In addition, the former showed an increasing year-on-year trend while the latter showed a decline. From 2005 to 2018, the proportion of farmland fell from 51.68 
to $37.59 \%$, while the proportion of built-up areas rose from 40.67 to $55.48 \%$. Although the proportion of built-up area in the other two levels was no more than $50 \%$, urban land had clearly replaced farmland as the most important land-use type in the SUHI FP. The phenomenon indicated that no matter the level of the city, it still underwent obvious urbanization, including outward expansion and densification. Moreover, Level 1 cities reached the largest proportion of built-up land, while the proportion of farmland, forest, and grassland was higher in Level 2 and Level 3 cities, thus showing that urbanization in these cities was incomplete. These findings can be important for assessing the degree of urbanization in cities of different levels.

Table 5. The proportion of SUHI FP to land use type area of Level 1, Level 2, and Level 3 cities (\%).

\begin{tabular}{|c|c|c|c|c|c|c|c|c|c|}
\hline \multirow{2}{*}{ Level } & \multirow{2}{*}{ Type } & \multicolumn{4}{|c|}{ Daytime } & \multicolumn{4}{|c|}{ Nighttime } \\
\hline & & 2005 & 2010 & 2015 & 2018 & 2005 & 2010 & 2015 & 2018 \\
\hline \multirow{6}{*}{ Level 1} & Farmland & 51.676 & 42.715 & 39.884 & 37.592 & 53.413 & 39.689 & 37.148 & 35.025 \\
\hline & Forest & 4.547 & 5.386 & 3.589 & 3.66 & 4.985 & 4.662 & 3.971 & 3.75 \\
\hline & Grassland & 0.146 & 0.142 & 0.124 & 0.359 & 0.306 & 0.222 & 0.152 & 0.719 \\
\hline & Water & 2.946 & 3.355 & 2.096 & 2.85 & 4.395 & 4.031 & 2.726 & 4.398 \\
\hline & Built-up land & 40.669 & 48.22 & 54.266 & 55.482 & 36.873 & 51.192 & 55.98 & 55.803 \\
\hline & Unused lands & 0.018 & 0.095 & 0.041 & 0.058 & 0.028 & 0.076 & 0.021 & 0.304 \\
\hline \multirow{6}{*}{ Level 2} & Farmland & 60.199 & 50.941 & 47.785 & 47.067 & 49.941 & 44.412 & 46.536 & 45.358 \\
\hline & Forest & 7.425 & 10.879 & 7.323 & 4.931 & 6.981 & 5.913 & 6.478 & 3.675 \\
\hline & Grassland & 1.862 & 1.181 & 1.338 & 0.967 & 2.901 & 3.1 & 2.308 & 2.325 \\
\hline & Water & 5.879 & 6.358 & 3.789 & 4.222 & 10.062 & 11.487 & 6.319 & 9.896 \\
\hline & Built-up land & 22.99 & 30.632 & 39.724 & 42.761 & 30.11 & 35.083 & 38.318 & 38.689 \\
\hline & Unused lands & 0.005 & 0.009 & 0.043 & 0.053 & 0 & 0.004 & 0.039 & 0.059 \\
\hline \multirow{6}{*}{ Level 3} & Farmland & 56.036 & 52.058 & 47.783 & 53.314 & 49.948 & 45.746 & 46.536 & 45.358 \\
\hline & Forest & 9.136 & 9.36 & 12.801 & 8.167 & 9.821 & 8.46 & 12.729 & 8.439 \\
\hline & Grassland & 5.342 & 5.487 & 5.892 & 5.434 & 5.213 & 5.597 & 4.28 & 4.584 \\
\hline & Water & 7.692 & 5.829 & 2.609 & 4.17 & 8.869 & 7.51 & 5.94 & 8.017 \\
\hline & Built-up land & 21.795 & 27.177 & 31.870 & 28.375 & 17.927 & 28.473 & 26.716 & 32.44 \\
\hline & Unused lands & 0 & 0.089 & 0.044 & 0.539 & 0 & 0.012 & 0.046 & 0.773 \\
\hline
\end{tabular}

\subsection{Limitations}

Several limitations are discussed in this section. First, this study only extracted and analyzed the SUHI FPs of the main metropolises within the urban administrative area. This made each city have only one center, so the area SUHI FPs calculated in this study were actually underestimated. The solution to this problem requires finer LST data support. Second, the authors concluded that the paddy field was the second-most common land type when discussing the relationship between land-use type and FP; however, because land-use data were recorded only in summer from year to year, the question of whether paddy fields turned to bare land due to seasonal change was not considered and that may have led to the overestimation of the proportion of paddy fields. Finally, although this paper used buffer rings to eliminate as many large areas of bare land as possible, the results still found a considerable proportion of bare land in the SUHI FPs. Due to the extremely significant effect of bare land on the LST, the quantitative calculation of a SUHI FP can be affected to a certain extent. In the future, higher resolution LST and land-use data should be employed to explore the impact of seasonal changes on land-use types when extracting FPs.

\section{Conclusions}

This study systematically analyzed the spatiotemporal changes of the FP in the YRDUA from 2005 to 2018. On this basis, the authors discussed not only the matching relationship between the attenuation curves of FPs and urban development patterns but also the overlay effect of the FP between adjacent cities. The FP was calculated using a 
logistical model, and the temporal changes were estimated by the SDE model. The relationship between the FP and urban development was obtained by clustering the temperature attenuation curves using the k-means method. The study resulted in three conclusions. First, the growth area of the FPs positively correlated with the city levels over time, but the expansion rate was more noticeable during the daytime. On a spatial scale, the evolution of the FPs in the YRDUA showed an overall trend from east to west. Second, three development patterns in the 27 cities were obtained by clustering the FP temperature attenuation curves. These coincided with the size classifications of the urban populations, indicating that the curve shape could become important for interpreting urban development patterns. Third, the LST curve between Wuxi and Changzhou proved that the superposition effect of SUHI FP can lead to an increase in LST at the fringe of the city when the urban areas of two cities are connected or adjacent. In general, compared with the traditional classification of cities by population size, the classification from a SUHI temperature curve is more scientific and targeted. Nowadays, FPs are continuously expanding, and the resulting aggregation and overlay is causing a series of environmental problems.

This research can help move the YRDUA into a period of high-quality development. The results not only help to provide a scientific foundation for an effective response to urban high temperature risks, but also provide suggestions for thermal environment research in other urban agglomerations.

Author Contributions: Conceptualization, F.T. and G.T.; methodology, F.T.; software, Y.H. and T.Z.; validation, F.T.; formal analysis, T.Z.; investigation, F.T.; data curation, Y.H.; writing-original draft preparation, F.T. and Y.H.; writing - review and editing, F.T. and T.Z.; visualization, Y.H.; supervision, G.T.; project administration, G.T.; funding acquisition, F.T., G.T. and T.Z. All authors have read and agreed to the published version of the manuscript.

Funding: This research was funded by the National Natural Science Foundation of China under Grant 41930102, 41301514, and 41401456, in part by the Natural Science and Technology Project of Nantong (MS12020075).

Institutional Review Board Statement: Not applicable.

Informed Consent Statement: Not applicable.

Data Availability Statement: Not applicable.

Acknowledgments: The authors would like to thank the editor and the anonymous reviewers who provided insightful comments on improving this paper.

Conflicts of Interest: The authors declare no conflict of interest.

$\begin{array}{ll}\text { Abbreviations } \\ \text { UHI } & \text { Urban heat island } \\ \text { SUHI } & \text { Surface urban heat island } \\ \text { SUHI FP } & \text { Surface urban heat island footprint } \\ \text { YRDUA } & \text { Yangtze River Delta urban agglomeration } \\ \text { SED } & \text { Standard deviation ellipse } \\ \text { LST } & \text { Land surface temperature } \\ \text { AUHI } & \text { Atmospheric urban heat island } \\ \text { SUHII } & \text { Surface urban heat island intensity } \\ \text { RESDC } & \text { Resource and Environment Data Cloud } \\ \text { Var } & \text { Variance } \\ \text { CV } & \text { Coefficient of variation } \\ \text { SSAP } & \text { Sum of slopes of adjacent points }\end{array}$

\section{References}

1. Madanian, M.; Soffianian, A.R.; Koupai, S.S.; Pourmanafi, S.; Momeni, M. The study of thermal pattern changes using Landsatderived land surface temperature in the central part of Isfahan province. Sustain. Cities Soc. 2018, 39, 650-661. [CrossRef]

2. Mohammad, P.; Goswami, A. A Spatio-Temporal Assessment and Prediction of Surface Urban Heat Island Intensity Using Multiple Linear Regression Techniques Over Ahmedabad City, Gujarat. J. Indian Soc. Remote Sens. 2021, 49, $1091-1108$. 
3. Voogt, J.A.; Oke, T.R. Thermal remote sensing of urban climates. Remote Sens. Environ. 2003, 86, 370-384. [CrossRef]

4. He, B.J. Potentials of meteorological characteristics and synoptic conditions to mitigate urban heat island effects. Urban Clim. 2018, 24, 26-33. [CrossRef]

5. Zhou, D.; Bonafoni, S.; Zhang, L.; Wang, R. Remote sensing of the urban heat island effect in a highly populated urban agglomeration area in East China. Sci. Total Environ. 2018, 628-629, 415-429. [CrossRef]

6. Lin, C.-Y.; Chen, F.; Huang, J.C.; Chen, W.-C.; Liou, Y.-A.; Chen, W.-N.; Liu, S.-C. Urban heat island effect and its impact on boundary layer development and land-sea circulation over northern Taiwan. Atmos. Environ. 2008, 42, 5635-5649. [CrossRef]

7. Seto, K.C.; Golden, J.S.; Alberti, M.; Turner, B.L. Sustainability in an urbanizing planet. Proc. Natl. Acad. Sci. USA 2017, 114, 8935-8938. [CrossRef]

8. Shahmohamadi, P.; Maulud, K.N.A.; Tawil, N.M.; Abdullah, N.A.G. The Impact of Anthropogenic Heat on Formation of Urban Heat Island and Energy Consumption Balance. Urban Stud. Res. 2011, 2011, 497524. [CrossRef]

9. Howard, L. The Climate of London: Deduced from Meteorological Observations, Made at Different Places in the Neighborhood of the Metropolis; Harvey and Darton: London, UK, 1818.

10. Mills, G. Luke Howard and the climate of London. Weather 2008, 63, 153-157. [CrossRef]

11. Zhang, Q.; Xu, D.; Zhou, D.; Yang, Y.; Rogora, A. Associations between urban thermal environment and physical indicators based on meteorological data in Foshan City. Sustain. Cities Soc. 2020, 60, 102288. [CrossRef]

12. Estoque, R.C.; Murayama, Y.; Myint, S.W. Effects of landscape composition and pattern on land surface temperature: An urban heat island study in the megacities of Southeast Asia. Sci. Total Environ. 2017, 577, 349-359. [CrossRef]

13. Ferguson, B.; Fisher, K.; Golden, J.; Hair, L.; Haselbach, L.; Hitchcock, D.; Kaloush, K.; Pomerantz, M.; Tran, N.; Waye, D. Reducing Urban Heat Islands: Compendium of Strategies-Cool Pavements; The National Academies of Sciences, Engineering, and Medicine: Washington, DC, USA, 2008.

14. Smoliak, B.V.; Snyder, P.K.; Twine, T.E.; Mykleby, P.M.; Hertel, W.F. Dense network observations of the Twin Cities canopy-layer urban heat island. J. Appl. Meteorol. Climatol. 2015, 54, 1899-1917. [CrossRef]

15. Schwarz, N.; Schlink, U.; Franck, U.; Großmann, K. Relationship of land surface and air temperatures and its implications for quantifying urban heat island indicators-An application for the city of Leipzig (Germany). Ecol. Indic. 2012, 18, 693-704. [CrossRef]

16. Mirzaei, P.A.; Haghighat, F. Approaches to study urban heat island-abilities and limitations. Build. Environ. 2010, 45, 2192-2201. [CrossRef]

17. Deilami, K.; Kamruzzaman, M.; Liu, Y. Urban heat island effect: A systematic review of spatio-temporal factors, data, methods, and mitigation measures. Int. J. Appl. Earth Obs. Geoinf. 2018, 67, 30-42. [CrossRef]

18. Weng, Q. Thermal infrared remote sensing for urban climate and environmental studies: Methods, applications, and trends. ISPRS J. Photogramm. Remote Sens. 2009, 64, 335-344. [CrossRef]

19. Hu, L.; Brunsell, N.A. A new perspective to assess the urban heat island through remotely sensed atmospheric profiles. Remote Sens. Environ. 2015, 158, 393-406. [CrossRef]

20. Renard, F.; Alonso, L.; Fitts, Y.; Hadjiosif, A.; Comby, J. Evaluation of the effect of urban redevelopment on surface urban heat islands. Remote Sens. 2019, 11, 299. [CrossRef]

21. Meng, Q.; Zhang, L.; Sun, Z.; Meng, F.; Wang, L.; Sun, Y. Characterizing spatial and temporal trends of surface urban heat island effect in an urban main built-up area: A 12-year case study in Beijing, China. Remote Sens. Environ. 2018, 204, 826-837. [CrossRef]

22. Deng, C.; Wu, C. BCI: A biophysical composition index for remote sensing of urban environments. Remote Sens. Environ. 2012, 127, 247-259. [CrossRef]

23. Rizwan, A.M.; Dennis, L.Y.C.; Chunho, L.I.U. A review on the generation, determination and mitigation of Urban Heat Island. J. Environ. Sci. 2008, 20, 120-128. [CrossRef]

24. Stewart, I.D. A systematic review and scientific critique of methodology in modern urban heat island literature. Int. J. Climatol. 2011, 31, 200-217. [CrossRef]

25. Zhou, D.; Zhao, S.; Zhang, L.; Sun, G.; Liu, Y. The footprint of urban heat island effect in China. Sci. Rep. 2015, 5, 2-12. [CrossRef]

26. Qiao, Z.; Wu, C.; Zhao, D.; Xu, X.; Yang, J.; Feng, L.; Sun, Z.; Liu, L. Determining the boundary and probability of surface urban heat island footprint based on a logistic model. Remote Sens. 2019, 11, 1368. [CrossRef]

27. Wang, J.; Huang, B.; Fu, D.; Atkinson, P.M. Spatiotemporal variation in surface urban heat island intensity and associated Determinants across major Chinese cities. Remote Sens. 2015, 7, 3670-3689. [CrossRef]

28. Li, Z.; Liu, L.; Dong, X.; Liu, J. The study of regional thermal environments in urban agglomerations using a new method based on metropolitan areas. Sci. Total Environ. 2019, 672, 370-380. [CrossRef]

29. Anniballe, R.; Bonafoni, S.; Pichierri, M. Spatial and temporal trends of the surface and air heat island over Milan using MODIS data. Remote Sens. Environ. 2014, 150, 163-171. [CrossRef]

30. Santamouris, M.; Paraponiaris, K.; Mihalakakou, G. Estimating the ecological footprint of the heat island effect over Athens, Greece. Clim. Chang. 2007, 80, 265-276. [CrossRef]

31. Tran, H.; Uchihama, D.; Ochi, S.; Yasuoka, Y. Assessment with satellite data of the urban heat island effects in Asian mega cities. Int. J. Appl. Earth Obs. Geoinf. 2006, 8, 34-48. [CrossRef]

32. Yang, Q.; Huang, X.; Tang, Q. The footprint of urban heat island effect in 302 Chinese cities: Temporal trends and associated factors. Sci. Total Environ. 2019, 655, 652-662. [CrossRef] [PubMed] 
33. Peng, J.; Liu, Q.; Xu, Z.; Lyu, D.; Wu, J. How to effectively mitigate urban heat island effect? A perspective of waterbody patch size threshold. Landsc. Urban Plan. 2020, 202, 103873. [CrossRef]

34. Liu, Y.; Fang, X.; Xu, Y.; Zhang, S.; Luan, Q. Assessment of surface urban heat island across China's three main urban agglomerations. Theor. Appl. Climatol. 2018, 133, 473-488. [CrossRef]

35. Li, J.; Wang, F.; Fu, Y.; Guo, B.; Zhao, Y.; Yu, H. A Novel SUHI Referenced Estimation Method for Multicenters Urban Agglomeration using DMSP/OLS Nighttime Light Data. IEEE J. Sel. Top. Appl. Earth Obs. Remote Sens. 2020, 13, 1416-1425. [CrossRef]

36. Huang, Q.; Lu, Y. The Effect of Urban Heat Island on Climate Warming in the Yangtze River Delta Urban Agglomeration in China. Int. J. Environ. Res. Public Heal. 2015, 12, 8773-8789. [CrossRef]

37. Li, B.; Liu, Z.; Nan, Y.; Li, S.; Yang, Y. Comparative Analysis of Urban Heat Island Intensities in Chinese, Russian, and DPRK Regions across the Transnational Urban Agglomeration of the Tumen River in Northeast Asia. Sustainability 2018, 10, 2637. [CrossRef]

38. Pal, S.; Xueref-Remy, I.; Ammoura, L.; Chazette, P.; Gibert, F.; Royer, P.; Dieudonné, E.; Dupont, J.-C.; Haeffelin, M.; Lac, C. Spatio-temporal variability of the atmospheric boundary layer depth over the Paris agglomeration: An assessment of the impact of the urban heat island intensity. AtmEn 2012, 63, 261-275. [CrossRef]

39. Yu, Z.W.; Yao, Y.; Yang, G.; Wang, X.; Vejre, H. Strong contribution of rapid urbanization and urban agglomeration development to regional thermal environment dynamics and evolution. For. Ecol. Manag. 2019, 446, 214-225. [CrossRef]

40. Chen, M.; Zhou, Y.; Hu, M.; Zhou, Y. Influence of urban scale and urban expansion on the urban heat island effect in metropolitan areas: Case study of Beijing-Tianjin-Hebei urban agglomeration. Remote Sens. 2020, 12, 3491. [CrossRef]

41. Guo, A.; Yang, J.; Xiao, X.; Xia, J.; Jin, C.; Li, X. Influences of urban spatial form on urban heat island effects at the community level in China. Sustain. Cities Soc. 2020, 53, 101972. [CrossRef]

42. Zhou, B.; Rybski, D.; Kropp, J.P. The role of city size and urban form in the surface urban heat island. Sci. Rep. 2017, 7, 4791. [CrossRef]

43. Fang, C.; Yao, S.M.; Liu, S.H. China's Urban Agglomeration Development Report; Science Press: Beijing, China, 2011.

44. Shen, Z.; Xu, X. Influence of the Economic Efficiency of Built-Up Land (EEBL) on Urban Heat Islands (UHIs) in the Yangtze River Delta Urban Agglomeration (YRDUA). Remote Sens. 2020, 12, 3944. [CrossRef]

45. Yu, Z.W.; Gao, J.; Wang, L.; Vejre, H. Suitability of regional development based on ecosystem service benefits and losses: A case study of the Yangtze River Delta urban agglomeration, China. Ecol. Indic. 2019, 107, 105579.

46. Yan, J.W.; Tao, F.; Zhang, S.Q.; Lin, S.; Zhou, T. Spatiotemporal distribution characteristics and driving forces of pm2.5 in three urban agglomerations of the yangtze river economic belt. Int. J. Environ. Res. Public Health 2021, 18, 2222. [CrossRef] [PubMed]

47. Du, H.; Wang, D.; Wang, Y.; Zhao, X.; Qin, F.; Jiang, H.; Cai, Y. Influences of land cover types, meteorological conditions, anthropogenic heat and urban area on surface urban heat island in the Yangtze River Delta Urban Agglomeration. Sci. Total Environ. 2016, 571, 461-470. [CrossRef]

48. Cheval, S.; Dumitrescu, A. The July urban heat island of Bucharest as derived from modis images. Theor. Appl. Climatol. 2009, 96, 145-153. [CrossRef]

49. Anniballe, R.; Bonafoni, S. A stable gaussian fitting procedure for the parameterization of remote sensed thermal images. Algorithms 2015, 8, 82-91. [CrossRef]

50. Quan, J.; Chen, Y.; Zhan, W.; Wang, J.; Voogt, J.; Wang, M. Multi-temporal trajectory of the urban heat island centroid in Beijing, China based on a Gaussian volume model. Remote Sens. Environ. 2014, 149, 33-46. [CrossRef]

51. Lefever, D.W. Measuring Geographic Concentration by Means of the Standard Deviational Ellipse. Am. J. Sociol. 1926, 32, 88-94. [CrossRef]

52. Wang, Z.; Liu, M.; Liu, X.; Meng, Y.; Zhu, L.; Rong, Y. Spatio-temporal evolution of surface urban heat islands in the Chang-ZhuTan urban agglomeration. Phys. Chem. Earth 2020, 117, 102865. [CrossRef]

53. Zhou, D.; Xiao, J.; Bonafoni, S.; Berger, C.; Deilami, K.; Zhou, Y.; Frolking, S.; Yao, R.; Qiao, Z.; Sobrino, J.A. Satellite remote sensing of surface urban heat islands: Progress, challenges, and perspectives. Remote Sens. 2019, 11, 48. [CrossRef]

54. Hoan, N.T.; Liou, Y.A.; Nguyen, K.A.; Sharma, R.C.; Tran, D.P.; Liou, C.L.; Cham, D.D. Assessing the effects of land-use types in surface urban heat islands for developing comfortable living in Hanoi City. Remote Sens. 2018, 10, 1965. [CrossRef] 